\title{
Effect of Heat Treatment on Microstructures and Mechanical Properties in a Full Lamellar PM TiAl Alloy
}

\author{
Meike Su, Zebao Lang ${ }^{\mathrm{b}}$, Lijing Zheng ${ }^{\mathrm{a}}$, Jie Yan ${ }^{\mathrm{a}}$, Kai Guan ${ }^{\mathrm{a}}, \mathrm{Hu}$ Zhang $^{\text {a* }}$ \\ ${ }^{a}$ School of Materials Science and Engineering, Beihang University, \\ 37 Xueyuan Road Beijing, 100191, PR China \\ ${ }^{\mathrm{b}}$ Aerospace Research Institute of Materials \& Processing Technology, \\ Beijing 100076, PR China
}

Received: December 4, 2011; Revised: April 3, 2012

\begin{abstract}
The effect of heat treatment on the microstructures and tensile properties of a powder metallurgical (PM) TiAl based alloy has been investigated in this paper. The near gamma (NG) microstructure is transformed to a full lamellar (FL) microstructure with an average grain size of $100 \mu \mathrm{m}$ by heat treatments. The lamellar spacing of FL structure decreases with the increase of cooling rate. For cooling rates of 5,10 and $50{ }^{\circ} \mathrm{C} / \mathrm{min}$, the lamellar spacing is $1.9,1.0$ and $0.8 \mu \mathrm{m}$ respectively. The room temperature tensile properties exhibit an increasing trend with decrease of lamellar spacing.
\end{abstract}

Keywords: TiAl based alloys, Heat treatment, tensile properties

\section{Introduction}

TiAl alloys are attractive for aerospace and automobile applications because of their low density, good hightemperature strength and acceptable oxidation resistance. Intensive research on the technology and applications of TiAl intermetallic alloys has been conducted for many years $^{1-6}$. However, the inherent poor ductility of TiAl alloys at ambient temperatures has limited their applications. Alloy design and development to improve their low-temperature ductility have become the major challenge for this alloy system. Depending on the composition and heat-treatment procedure, four microstructures of $\gamma$-TiAl, i.e., near $\gamma(\mathrm{NG})$, duplex (DP), near lamellar (NL) and fully lamellar (FL), can be obtained. It has been established that those alloys with a fine fully lamellar (FL) microstructure possess good balanced mechanical properties ${ }^{7,8}$. Actually, the mechanical behavior of these alloys strongly depends on their crystallographic texture and microstructure, evolve during the fabrication processes ${ }^{9}$. The TiAl alloys can be fabricated by traditional casting and ingot metallurgy, but the process may cause of coarse-grained lamellar, a sharp casting texture, and chemical inhomogeneity in the microstructure ${ }^{10}$. A potential method of overcoming these problems is to use the powder metallurgy (PM) route. In compared of common ingot metallurgy, PM have advantage in eliminating compositional segregation, realizing the macro net-shape forming, and can effectively solve the TiAl intermetallic shaping of difficulty ${ }^{11-13}$. It is one of the main preparations for TiAl alloys. Recently, PM technique has attracted more and more interest due to the improvement in powder production and consolidation techniques such as hot isostatic pressing and current auxiliary sintering ${ }^{14,15}$.

Recently, numerous works have been conducted on the PM TiAl alloys. But only a limited amount of microstructure control work by heat treatment has been reported on

*e-mail: zhanghu@buaa.edu.cn
PM TiAl alloys when compared to IM-processed alloys. The objective of this paper is to study the effects of heat treatment on the phase transformation and microstructural development in a PM TiAl alloy. The room temperature tensile properties of full lamellar microstructures after heat treatment are also studied.

\section{Experimental}

The alloy used in this study has a nominal composition of PM Ti-46Al-2Cr-2Nb-(W, B) (at. \%) and provided by Aerospace Research Institute of Materials \& Processing Technology (ARIMT). The specimens of $\Phi 15 \times 80 \mathrm{~mm}$ were cut by electro-discharge machining (EDM) and subsequently heat treated in a box furnace in an argon atmosphere.

The heat treatment route is illustrated in Figure 1. The specimens were treated in $\alpha$ phase field $\left(1340^{\circ} \mathrm{C}\right)$ for 1 hour followed by cooling to $900{ }^{\circ} \mathrm{C}$ with different cooling rates $\left(5,10,50{ }^{\circ} \mathrm{C} / \mathrm{min}\right)$, and finally cooled in air (AC) to RT. After first heat treatment, the specimens were again heated to a temperature in the $\alpha_{2}+\gamma$ phase region at $1000{ }^{\circ} \mathrm{C}$ for 4 hours, followed by AC. Metallographic specimens were prepared by standard mechanical polishing method and then etched in a mixed solution of $90 \mathrm{~mL} \mathrm{H}_{2} \mathrm{O}, 30 \mathrm{~mL} \mathrm{HNO}_{3}$ and $10 \mathrm{~mL}$ HF. The microstructures were studied by an Olympus BX51M optical microscope, a JSM-5800 and a CS-3400 scanning electron microscope (SEM).

The room temperature tensile properties were tested using flat samples. In order to avoid the random and systematic error the mechanical properties measurements, at least three tensile specimens were prepared for each material condition. Figure 2 indicates the size and section shape of the room temperature tensile specimen which was fabricated by electric discharge cutting and polished before test. Tensile tests were carried out using an Instron5565 at room temperature. 


\section{Results}

\subsection{Microstructure}

The primary specimens have a NG structure with an average colony size of $\sim 5 \mu \mathrm{m}$. The microstructure looks compact and uniform, neither porosity nor micro-cracks are found (Figure 3).

Figure 3 Primary microstructure of PM Ti-46Al-2Cr$2 \mathrm{Nb}-(\mathrm{B}, \mathrm{W})$ alloy To obtain a FL structure, the samples were

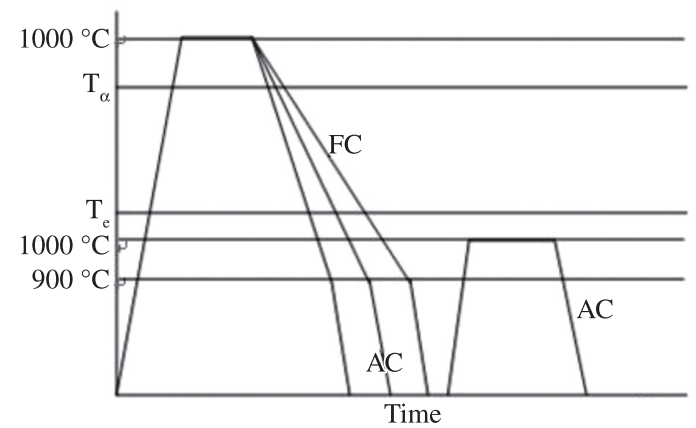

Figure 1. Schematic of heat treatment routes (FC: furnace cooling; AC: air cooling; $\mathrm{T}_{\mathrm{e}}$ : eutectoid temperature; $\mathrm{T}_{\alpha}: \alpha$ transformation temperature)
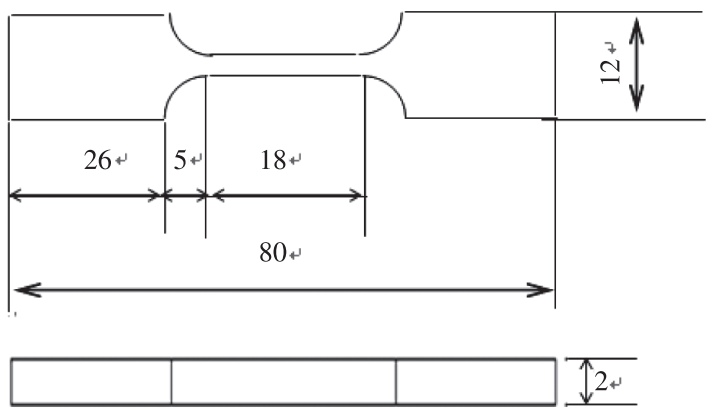

Figure 2. Geometric shape and size of room temperature tensile specimen in $\mathrm{mm}$.

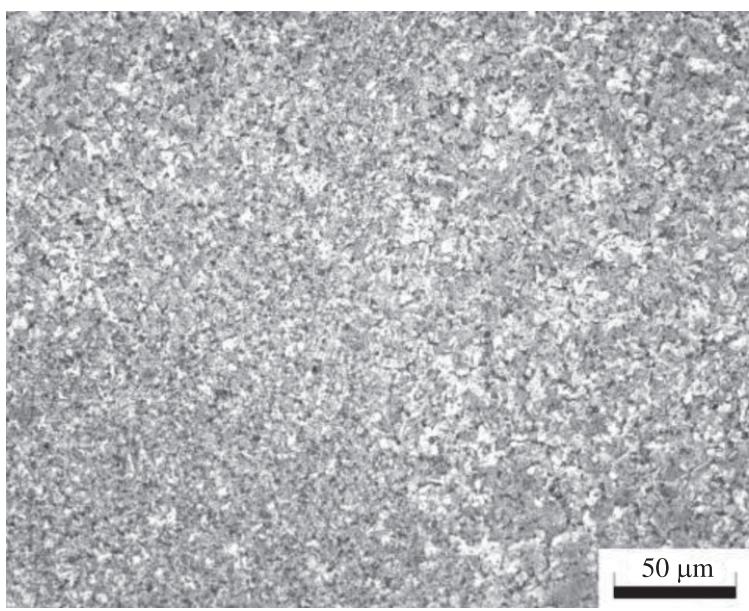

(a) subjected to heat treatment at $1340^{\circ} \mathrm{C}$ for 1 hour followed by $\mathrm{FC}$ to $900{ }^{\circ} \mathrm{C}$ and then $\mathrm{AC}$ to RT. Figure 4 shows the optical micrographs of the PM Ti-46Al-2Cr-2Nb-(W, B) alloy after heat treatment at different cooling rates. It can be seen that the primary NG microstructure has been replaced by new FL microstructure. The formation of lamellar structure after heat treatment indicates that NG microstructure is transformed into single $\alpha$ phase during holding at $1340{ }^{\circ} \mathrm{C}$, and lamellar structure is formed during cooling via the precipitation of $\gamma$ plates in the $\alpha$ grains during cooling after heat treatment ${ }^{16}$. When three different cooling rates are compared, it is evident that cooling rate has no marked influence on the optical microstructure morphology; fully lamellar structures with the same average grain size of about $100 \mu \mathrm{m}$ are produced by heat treatments. However some large lamellar colonies with grain size more than $200 \mu \mathrm{m}$ are found in the structure, while the small-sized grains are below $50 \mu \mathrm{m}$ (Figure $4 \mathrm{a}, \mathrm{b}$ and c).

Figure 5 shows the BSE image of the lamellar morphology of structures obtained at different cooling rates. It is apparent that cooling rate has an effect on lamellar spacing. As seen in Figure 5a, lamellar spacing is $1.9 \mu \mathrm{m}$ for this slow cooling rate of $5^{\circ} \mathrm{C} / \mathrm{min}$ compared to $0.8 \mu \mathrm{m}$ lamellar spacing for the fast cooling rate of $50{ }^{\circ} \mathrm{C} / \mathrm{min}$ (Figure $5 \mathrm{c}$ ). Heat treatment followed by a cooling rate of $10{ }^{\circ} \mathrm{C} / \mathrm{min}$ results in a lamellar spacing of $1.0 \mu \mathrm{m}$ (Figure 5b). It is quite obvious that spacing is reduced with increasing cooling rate. The relationship between cooling rate and lamellar spacing is schematically illustrated in Figure 6.

Figure 6 Variation of lamellar spacing with cooling rate 3.2 Room temperature tensile properties Tensile properties of materials with different heat treatment processing conditions were measured at room temperature. Table 1 shows the results. It is clear that a faster cooling rate yields enhanced room temperature properties. The samples with the cooling rate of $5{ }^{\circ} \mathrm{C} / \mathrm{min}$ show a mean tensile elongation of $0.54 \%$ and fracture strength of $422 \mathrm{MPa}$. As the cooling rate increases from $5{ }^{\circ} \mathrm{C} / \mathrm{min}$ to $10^{\circ} \mathrm{C} / \mathrm{min}$, the RT elongation increases from 0.54 to $0.70 \%$, while fracture strength also increases from 422 to $467 \mathrm{MPa}$. The

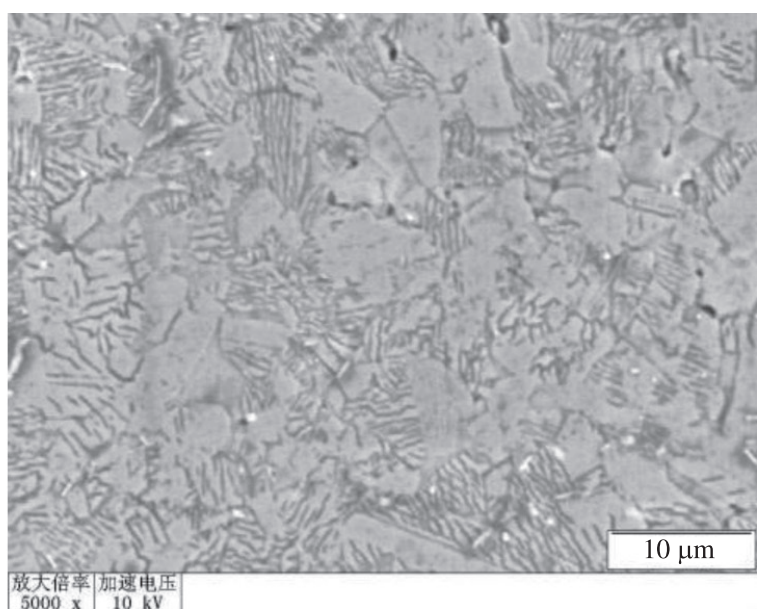

(b)

Figure 3. Primary microstructure of PM Ti-46Al-2Cr-2Nb-(B, W) alloy. 


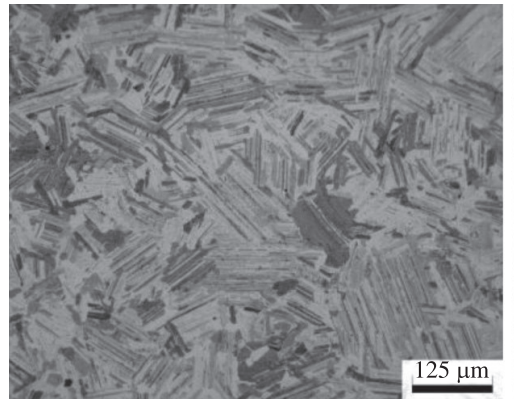

(a)

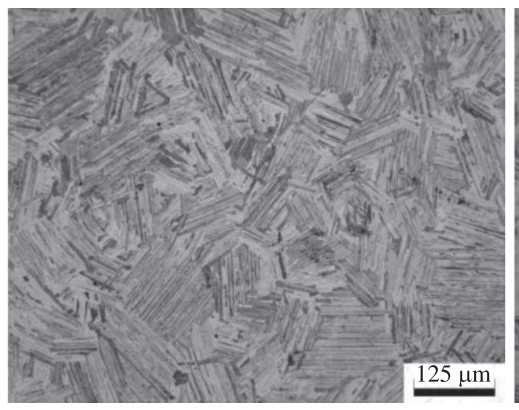

(b)

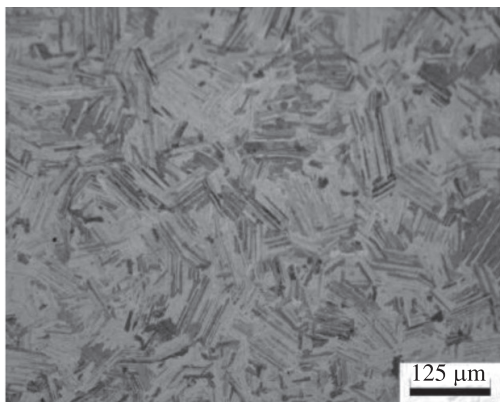

(c)

Figure 4. Microstructures of the alloy after different cooling rate a) $5^{\circ} \mathrm{C} / \mathrm{min}$; b) $10{ }^{\circ} \mathrm{C} / \mathrm{min}$; c) $50{ }^{\circ} \mathrm{C} / \mathrm{min}$.

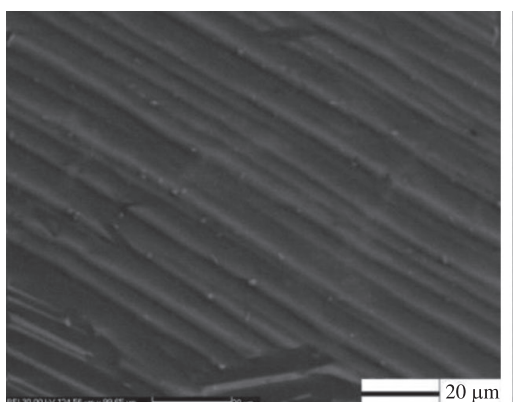

(a)

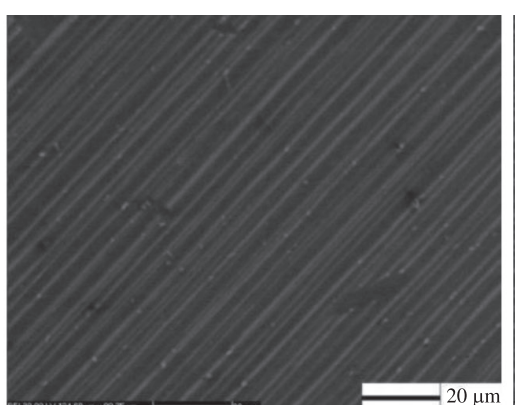

(b)

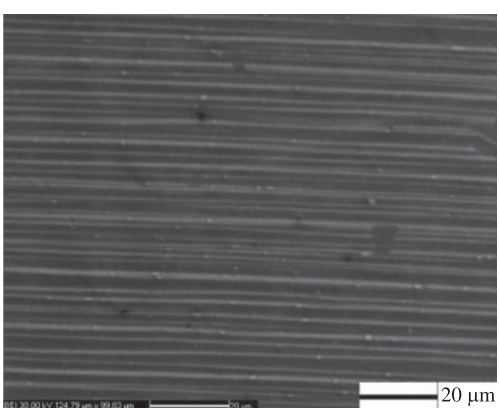

(c)

Figure 5. BSE images of lamellar morphology after different cooling rate a) $5{ }^{\circ} \mathrm{C} / \mathrm{min}$; b) $10{ }^{\circ} \mathrm{C} / \mathrm{min}$; c) $50{ }^{\circ} \mathrm{C} / \mathrm{min}$.

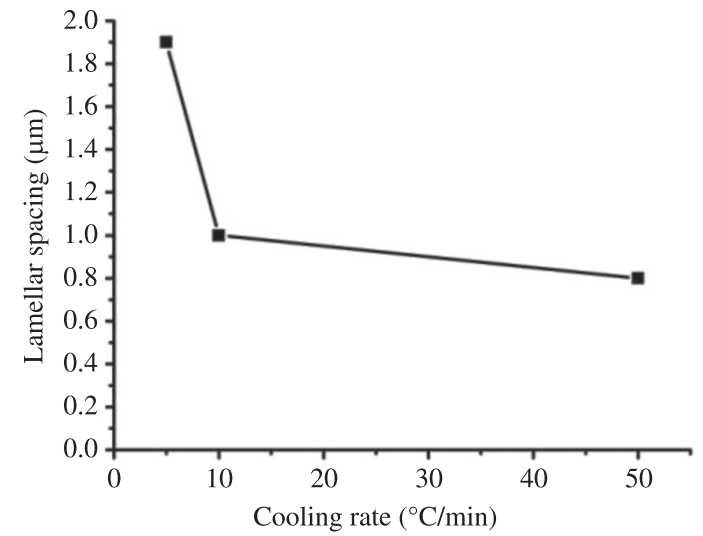

Figure 6. Variation of lamellar spacing with cooling rate.

Table 1. Room temperature tensile properties of PM alloys after heat treatment Cooling rate $\left({ }^{\circ} \mathrm{C} / \mathrm{min}\right)$ Elongation (\%)Fracture strength (MPa).

\begin{tabular}{rllcccc}
\hline & Max & Min & Mean & Max & Min & Mean \\
\hline 5 & 0.59 & 0.45 & 0.54 & 443 & 406 & 422 \\
10 & 0.82 & 0.57 & 0.70 & 500 & 434 & 467 \\
50 & 1.0 & 0.56 & 0.78 & 484 & 467 & 475 \\
\hline
\end{tabular}

samples cooled at $50{ }^{\circ} \mathrm{C} / \mathrm{min}$ have the best ductility with elongation of $0.78 \%$ and fracture strength of $475 \mathrm{MPa}$. The relationship between cooling rate and room temperature tensile properties is schematically illustrated in Figure 7.

The fracture surfaces of the tensile samples are shown in Figure 8. The fracture morphologies after the tensile tests

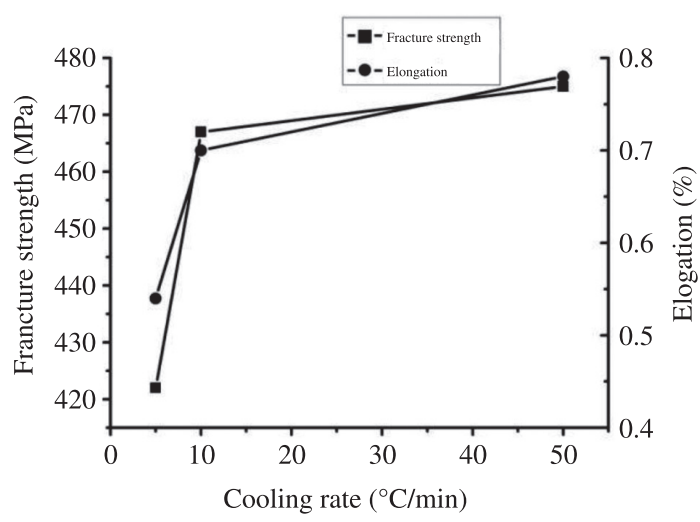

Figure 7. Variation of room temperature tensile properties with cooling rate.

are quite similar for the three microstructures with different cooling rates (Figure 8a,c and e). The fracture surfaces of the samples show predominantly transgranular cleavage fracture over the entire fracture surface. In all cases, the fracture modes are brittle fracture, no dimples are observed. In addition, all the fracture surfaces samples show some large regions as shown in Figure 8b, $\mathrm{d}$ and $\mathrm{f}$, marked by the white arrows. It seems reasonable to deduce that the fracture path tends to pass through the large lamellae grains.

\section{Discussion}

Mechanical properties of TiAl alloys have been proved to depend strongly on microstructure and hence considerable changes in these properties can be brought about by 
microstructural modifications. It is established that $\mathrm{TiAl}$ alloys with a predominant lamellar microstructure have good comprehensive performance ${ }^{17}$. In this study, using the $\mathrm{NG}$ as a starting structure, every $\gamma$ grain would be divided to four new $\alpha$ grains by the process of heating in the single $\alpha$ region. This is because $\gamma$ phase in TiAl alloys has four habit planes for the precipitation of $\alpha$ phase. In order to eliminate the $\gamma$ grain completely and to achieve full transformation to $\alpha$ phase, the specimen should be heated to $\alpha$ phase field. FL structure forms by precipitation of $\gamma$ laths on the $\alpha$ matrix with an orientation relationship of $\{111\} \gamma / /(0001) \alpha_{2},<110>$ $\gamma / /<1120>\alpha_{2}$ during cooling ${ }^{18}$.

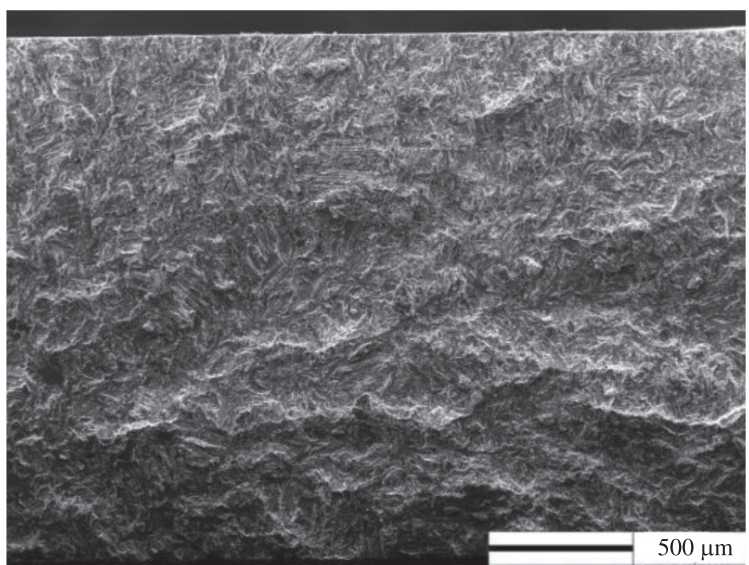

(a)

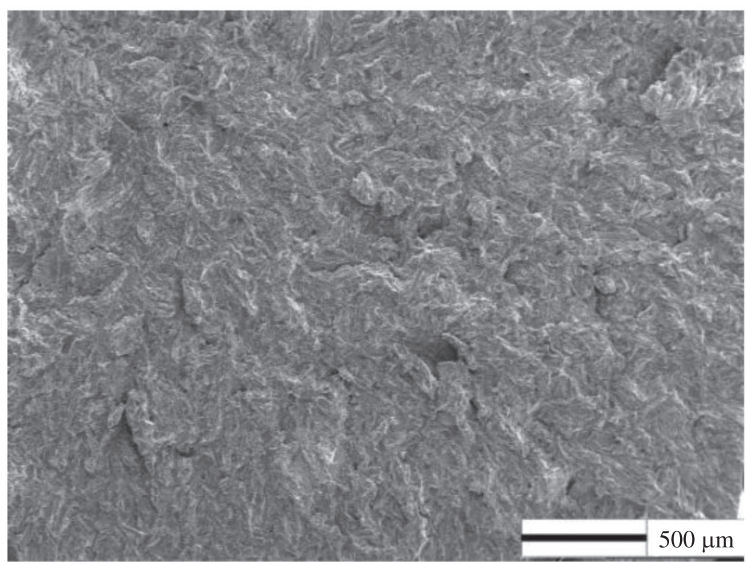

(c)

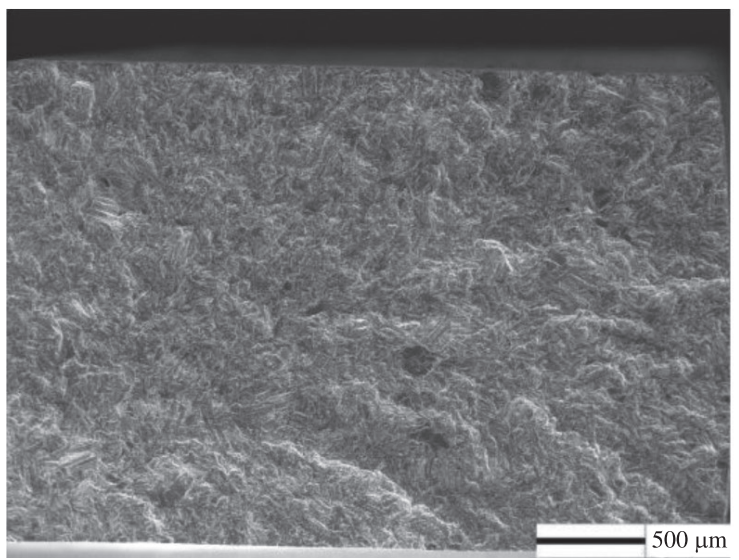

(e)

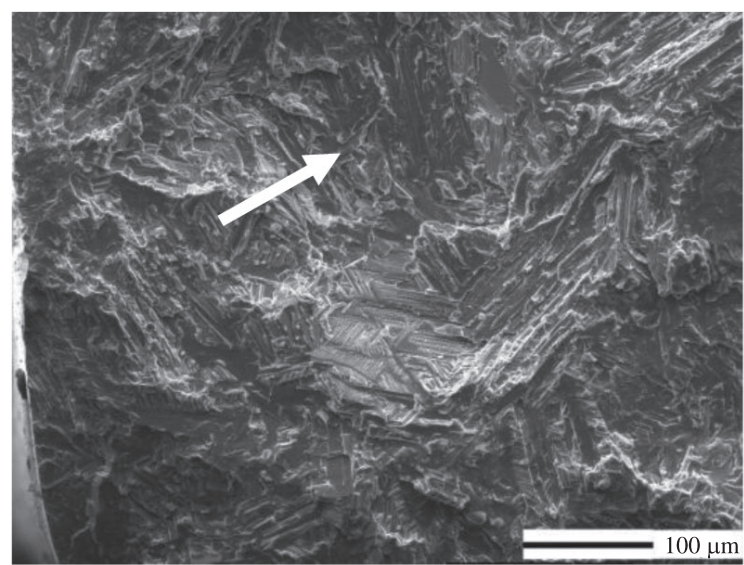

(b)

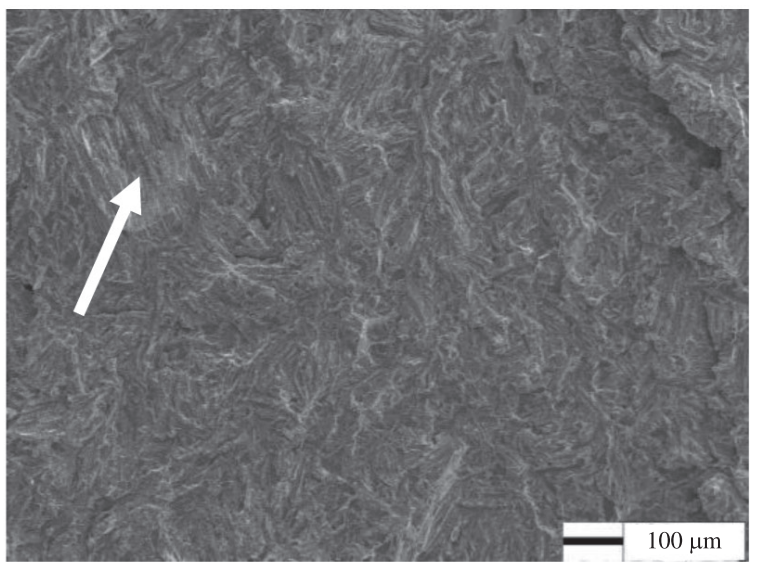

(d)

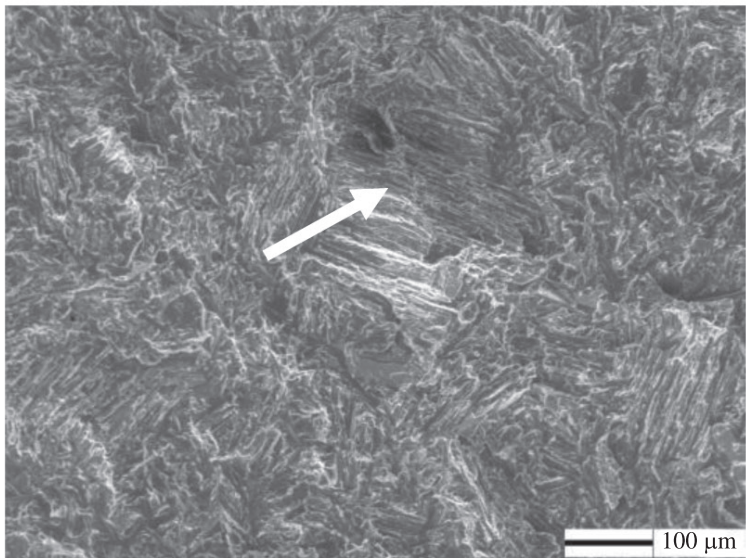

(f)

Figure 8. SEM photographs of the fracture surfaces (a), (b) $5{ }^{\circ} \mathrm{C} / \mathrm{min}$; (c), (d) $10{ }^{\circ} \mathrm{C} / \mathrm{min}$; (e), (f) $50{ }^{\circ} \mathrm{C} / \mathrm{min}$. 
Thus, FL structure can be obtained from initial $\gamma$ structure. However, several parameters must be strictly controlled. The holding temperature should not be too high and the hold time should not be too long. If the holding time is too short, the resultant microstructure is DP or nearly FL at best. On contrary, if the hold time is too long, $\alpha$ grain growth becomes very fast. The relationship between grain growth and parameters can be given as ${ }^{19}$ :

$\left(\begin{array}{cc}-2 & -2 \\ \log _{t} D_{0}\end{array}\right)=\log K-\frac{Q m}{2.3 R T}$

Where $\stackrel{-2}{D_{0}}$ and $\stackrel{-2}{D_{t}}$ are the mean grain sizes before and after holding at a temperature $\mathrm{T}$ for a period of time $\mathrm{t}, \mathrm{Qm}$ is the activation energy for the movement of grain boundaries, and $\mathrm{K}$ and $\mathrm{R}$ are constants. Obviously, a higher $\mathrm{T}$ will results in a larger grain size. Usually, in most cast TiAl alloys the alph agrains can grow to about $1000 \mathrm{~mm}$ in diameter in a few minutes when treated in $\alpha$ phase field ${ }^{20}$. The present study shows that a FL microstructure with a colony size of below $100 \mu \mathrm{m}$ can be obtained in PM TiAl after $1340^{\circ} \mathrm{C} / 1 \mathrm{~h}$ heat treatment processing. Two reasons may be considered: 1) The initial grain size of this PM TiAl alloy is especial fine compared to the casting structure. 2) Minor addition of boron prevents the grains from growing rapidly during holding in the single $\alpha$ phase field ${ }^{21}$.

During cooling from $\alpha$ phase field, the longitudinal and lateral growth of the lamellar precipitates occurs through the "terrace-ledge-kink" mechanism"22. This mechanism can be described as a lateral growth of the lamellae through the movement of Shockley partials on the habit plane, leading to the formation of ledges on the phase-interfaces. The composition change of the growing lamella is ensured by the transfer of atoms onto kinks which provide sites to the atomic attachment ${ }^{7}$. For faster cooling rate, the greater driving accelerates the speed of the atoms.

And the lamellar spacing of FL structure decreases with the increase of cooling rate in the heat treatment process. This is consistent with the previous results ${ }^{23}$.

\section{References}

1. Kim YW. Microstructural evolution and mechanical properties of a forged gamma titanium aluminide alloy. Acta Metallurgica et Materialia. 1992; 10:1121-1134. http://dx.doi. org/10.1016/0956-7151(92)90411-7

2. Takeyama M. Microstructural evolution and tensile properties of titanium-rich TiAl alloy. Materials Science and Engineering: A. 1992; 152:269-276. http://dx.doi.org/10.1016/09215093(92) $90078-\mathrm{F}$

3. Su Y, Liu X, Luo L, Zhao L, Guo J and Fu H. Deoxidation of Ti-Al intermetallics via hydrogen treatment. International Journal of Hydrogen Energy. 2010; 35:9214-9217. http:// dx.doi.org/10.1016/j.ijhydene.2010.05.115

4. Su Y, Liu C, Li X, Guo J, Li B, Jia J et al. Microstructure selection during the directionally peritectic solidification of Ti-Al binary system. Intermetallics. 2005; 13:267-274. http:// dx.doi.org/10.1016/j.intermet.2004.07.010

5. Yanqing S, Jingjie G, Jun J, Guizhong L and Yuan L. Composition control of a TiAl melt during the induction skull
This study reveals that both the fracture strength and elongation increase with a decrease in the lamellae spacing. In the FL TiAl alloys with about $100 \mu \mathrm{m}$ of grain size, the elongation increases with the decrease of lamellar spacing, because for a given area there are more lamellas to serve as a barrier to dislocation movement, which is essential for any plastic deformation. The fracture strength increases with the decrease of lamellar spacing too, because a small lamellae spacing hinders translamellar microcracking, and linkage of the main crack with interlamellar microcracks thus becomes difficult. In contrast, a large lamellae spacing favors translamellar microcracking and linkage of the main crack with translamellar and interlamellar microcracks becomes relatively easy ${ }^{24}$. It is shown that the elongation from 0.54 to $0.78 \%$, mean fracture strength increase from $422 \mathrm{MPa}$ to $475 \mathrm{MPa}$ when the lamellae spacing increases from 1.9 to $0.8 \mu \mathrm{m}$.

It is worth noting that, although fine FL structure of $100 \mu \mathrm{m}$ is obtained, but some areas comprising of large grains are also observed. Therefore more research on refining of grain size and microstructure uniformity should be carried out to further improve the room temperature properties in PM TiAl alloy.

\section{Conclusions}

The NG microstructure of PM Ti-46Al-2Cr-2Nb (B, W) alloy is transformed to FL structure with size of $100 \mu \mathrm{m}$ by heat treatment at $1340{ }^{\circ} \mathrm{C} / 1 \mathrm{~h}$ followed by cooling. It is found that cooling rate of heat treatment has an effect on lamellar spacing: spacing is reduced with increasing cooling rate. For cooling rates of $5,10,50{ }^{\circ} \mathrm{C} / \mathrm{min}$, the lamellar spacing is $1.9,1.0,0.8 \mu \mathrm{m}$ respectively. The room temperature tensile properties increase with the lamellar spacing decreasing. In this experiment, when the cooling rate is $50{ }^{\circ} \mathrm{C} / \mathrm{min}$, samples have the best tensile properties with maximum elongation and fracture strength of $1.0 \%$ and $484 \mathrm{MPa}$ respectively.

melting (ISM) process. Journal of Alloys and Compounds. 2002; 334:261-266. http://dx.doi.org/10.1016/S09258388(01)01766-2

6. Su Y-Q, Guo J-J, Liu G-Z, Jia J and Ding H-S. Temperature control of TiAl melt during induction skull melting. Materials Science and Technology. 2001; 17:1434-1440.

7. Kim YW. Ordered intermetallic alloys, part III: gamma titanium aluminides. Journal of Metals. 1994; 46(7):30-39.

8. Chan KS and Kim YW. Effects of lamellae spacing and colony size on the fracture resistance of a fully-lamellar TiAl alloy. Acta Materialia. 1995; 43(2):439-451. http://dx.doi. org/10.1016/0956-7151(94)00278-P

9. Lasalmonie A. Intermetallics: Why is it so difficult to introduce them in gas turbine engines? Intermetallics. 2006; 14:11231129. http://dx.doi.org/10.1016/j.intermet.2006.01.064

10. Imayev RM, Imayev VM, Oehring M and Appel F. Alloy design concepts for refined gamma titanium aluminide based alloys. 
Intermetallics. 2007; 15:451-460. http://dx.doi.org/10.1016/j. intermet.2006.05.003

11. Yolton $\mathrm{CF}$, Habel $\mathrm{U}$ and Clemens $\mathrm{H}$. Advanced particulate materials and processes. Princeton: Metal Powder Industries Federation; 1997. $161 \mathrm{p}$.

12. Liu B, Liu Y, Zhang W and Huang JS. Hot deformation behavior of TiAl alloys prepared by blended elemental powders. Intermetallics. 2011; 19:154-159. http://dx.doi.org/10.1016/j. intermet.2010.08.024

13. Nadakuduru VN, Zhang DL, Cao P, Chiu YL and Gabbitas $\mathrm{B}$. The mechanical behaviour of an ultrafine grained Ti$47 \mathrm{Al}-2 \mathrm{Cr}$ (at\%) alloy in tension and compression and at different temperature. Materials Science and Engineering: A. $2011 ; 528: 4592-4599$. http://dx.doi.org/10.1016/j. msea.2011.02.045

14. Gerling R, Clemens $\mathrm{H}$ and Schimansky FP. Powder metallurgical processing of intermetallic gamma titanium aluminides. Advanced Engineering Materials. 2004; 6:23-38. http://dx.doi.org/10.1002/adem.200310559

15. Wang YH, Lin JP, He YH, Wang YL and Chen GL. Fabrication and SPS microstructures of Ti-45Al-8.5Nb-(W, B, Y) alloying powders. Intermetallics. 2008; 16: 215-224. http://dx.doi. org/10.1016/j.intermet.2007.09.010

16. Beddoes JC, Zhao L and Wallace W. The microstructural response of near $\gamma$-TiAl+W to heat treatment. Scripta Metallurgica et Materialia. 1993; 28:383-388. http://dx.doi. org/10.1016/0956-716X(93)90446-Y
17. Kim YW. Microstructural evolution and mechanical properties of a forged gamma titanium aluminide alloy. Acta Metallurgica. 1992; 40:1121-1134. http://dx.doi. org/10.1016/0956-7151(92)90411-7

18. Blackburn MJ. The Science Technology and Application of Titanium. Oxford: Pergamon Press; 1970. 633 p.

19. Hu GX and Qian MG. Fundamental of Physical Metallurgy. Shanghai: Shanghai Science and Technology Press; 1980. $328 \mathrm{p}$.

20. Darolia R, Lewandowski JJ, Liu CT, Martin PL, Miracle DB and Nathal MV. Structural intermetallics. In: Proceedings of the First International Symposium on Structural Intermetallics; 1993; Fuchs. Fuchs, 1993. p. 195.

21. Cheng TT. The mechanism of grain refinement in TiAl alloys by boron addition - an alternative hypothesis. Intermetallics. 2000; 8:29-37. http://dx.doi.org/10.1016/ S0966-9795(99)00063-1

22. Howe JM, Dahmen U and Gronsky R. Atomic mechanisms of precipitate plate growth. Philosophical Magazine A. 1987; 56:31-61. http://dx.doi.org/10.1080/01418618708204465

23. Zheng Y. Microstructure evolution during heat treatment of $\mathrm{TiAl}+\mathrm{Ti}_{3} \mathrm{Al}$ alloy. Scripta Metallurgica et Materialia. 1992; 26:27-28. http://dx.doi.org/10.1016/0956716X(92)90176-F

24. Chan KS and Kim Y-W . Effects of lamellae spacing and colony size on the fracture resistance of a fully-lamellar TiAl alloy. Acta Metallurgica. 1995; 43:439-451. http://dx.doi. org/10.1016/0956-7151(94)00278-P 